\title{
Survey of childhood empyema in Asia: Implications for detecting the unmeasured burden of culture-negative bacterial disease Batmunkh Nyambat*1, Paul E Kilgore ${ }^{1}$, Dong Eun Yong2, Dang Duc Anh ${ }^{3}$, Chen-Hsun Chiu ${ }^{4}$, Xuzhuang Shen ${ }^{5}$, Luis Jodar ${ }^{1}$, Timothy L Ng6, Hans L Bock ${ }^{6}$ and William P Hausdorff6
}

Address: ${ }^{1}$ Division of Translational Research, International Vaccine Institute, Seoul, South Korea, ${ }^{2}$ Department of Laboratory Medicine, College of Medicine, Yonsei University, Seoul, South Korea, ${ }^{3}$ National Institute of Hygiene and Epidemiology, Hanoi, Vietnam, ${ }^{4}$ Chang Gung Children's Hospital and Chang Gung University College of Medicine, Taipei, Taiwan, ${ }^{5}$ Beijing Children's Hospital affiliated to Capital Medical University, Beijing, PR China and ${ }^{6}$ GlaxoSmithKline Biologicals, Rixensart, Belgium

Email: Batmunkh Nyambat* - bnyam@ivi.int; Paul E Kilgore - pkilgore@ivi.int; Dong Eun Yong - deyong@yumc.yonsei.ac.kr; Dang Duc Anh - ducanhnihe@hn.vnn.vn; Chen-Hsun Chiu - chchiu@adm.cgmh.org.tw; Xuzhuang Shen - xuzhuangshen@163.com; Luis Jodar - ljodar@ivi.int; Timothy L Ng - timothy.l.ng@gsk.com; Hans L Bock - Hans.L.Bock@gsk.com;

William P Hausdorff - William.P.Hausdorff@gsk.com

* Corresponding author

Published: II July 2008

BMC Infectious Diseases 2008, 8:90 doi:10.1 186/147/-2334-8-90

This article is available from: http://www.biomedcentral.com/147/-2334/8/90

(c) 2008 Nyambat et al; licensee BioMed Central Ltd.

This is an Open Access article distributed under the terms of the Creative Commons Attribution License (http://creativecommons.org/licenses/by/2.0), which permits unrestricted use, distribution, and reproduction in any medium, provided the original work is properly cited.
Received: 29 January 2008

Accepted: II July 2008

which permits unrestricted use, distribution, and reproduction in any medium, provided the onignal work is properly cited.

\begin{abstract}
Background: Parapneumonic empyema continues to be a disease of significant morbidity and mortality among children despite recent advances in medical management. To date, only a limited number of studies have assessed the burden of empyema in Asia.

Methods: We surveyed medical records of four representative large pediatric hospitals in China, Korea, Taiwan and Vietnam using ICD-I0 diagnostic codes to identify children < 16 years of age hospitalized with empyema or pleural effusion from I995 to 2005. We also accessed microbiology records of cultured empyema and pleural effusion specimens to describe the trends in the epidemiology and microbiology of empyema.
\end{abstract}

Results: During the study period, we identified I,379 children diagnosed with empyema or pleural effusion $($ China, $\mathrm{n}=46 \mathrm{I}$; Korea, $n=134$; Taiwan, $n=119$; Vietnam, $n=665$ ). Diagnoses of pleural effusion $(n=1,074)$ were 3.5 times more common than of empyema $(n=305)$, although the relative proportions of empyema and pleural effusion noted in hospital records varied widely between the four sites, most likely because of marked differences in coding practices. Although pleural effusions were reported more often than empyema, children with empyema were more likely to have a cultured pathogen. In addition, we found that median age and gender distribution of children with these conditions were similar across the four countries. Among I,379 empyema and pleural effusion specimens, 401 (29\%) were culture positive. Staphylococcus aureus $(n=126)$ was the most common organism isolated, followed by Streptococcus pneumoniae $(n=83)$, Pseudomonas aeruginosa $(n=37)$ and Klebsiella $(n=35)$ and Acinetobacter species $(\mathrm{n}=34)$.

Conclusion: The age and gender distribution of empyema and pleural effusion in children in these countries are similar to the US and Western Europe. S. pneumoniae was the second leading bacterial cause of empyema and pleural effusion among Asian children. The high proportion of culture-negative specimens among patients with pleural effusion or empyema suggests that culture may not be a sufficiently sensitive diagnostic method to determine etiology in the majority of cases. Future prospective studies in different countries would benefit from standardized case definitions and coding practices for empyema. In addition, more sensitive diagnostic methods would improve detection of pathogens and could result in better prevention, treatment and outcomes of this severe disease. 


\section{Background}

Globally, respiratory diseases are a leading cause of morbidity and mortality among both children and adults $[1,2]$. In developing countries, children less than 5 years of age are at high risk for severe, life-threatening disease associated with bacterial and viral pathogens [3]. Streptococcus pneumoniae is a major respiratory pathogen, and the spectrum of clinical presentations highly associated with this pathogen includes bacteremic and non-bacteremic presentations of pneumonia as well as parapneumonic effusions or empyema $[4,5]$.

Several studies from developed countries suggest that the prevalence of empyema and pleural effusion may be increasing [6-10]. In these countries, pediatric empyema is often quickly identified and treated promptly with surgical intervention or pharmacologic therapy [11,12]. Nevertheless, empyema is associated with prolonged hospitalization stays (mean $\sim 7$ days) and with a casefatality rate of about $5-7 \%$ [13]. While predictors of empyema in hospitalized children are not well-known, it appears that host factors may play a predisposing role [14]. In developing countries, severe pneumonia in children may be associated with necrotizing changes in a unilateral or bilateral pattern $[15,16]$. In developing countries, antecedent conditions such as malnutrition, measles or infection with antibiotic-resistant organisms may increase the risk of severe pneumonia accompanied by empyema $[17,18]$. In South Korea, the 7 -valent conjugate pneumococcal vaccine (PCV7) was licensed in 2002 and coverage has reached to $\sim 30 \%$ in the infant age group [19]. In Taiwan, PCV7 was introduced in 2006 and coverage is $<10 \%$. In both Korea and Taiwan, pneumococcal polysaccharide vaccines (PPV) are available but uptake has been low in older children and adults [20]. In China and Vietnam, the PCV7 has not been licensed (likely to occur in next 2 years) and uptake of PPV has also been slow and coverage is low $(\sim 1 \%)$.

The mean age of children with empyema and pleural effusion in developed country studies is 3-6 years with $50 \%$ to $80 \%$ of cases occurring in males [21-23]. In previous studies, bacterial pathogens that included Staphylococcus aureus, S. pneumoniae, Streptococcus pyogenes and Haemophilus influenzae type b (Hib) were associated with empyema in children [24,25]. However, an emerging body of literature now suggests that $S$. pneumoniae in particular is a major cause of empyema and that selected serotypes of pneumococcus may play an important role in this emerging disease pattern [10].

In the Asia-Pacific region, a limited number of clinical and laboratory studies suggest that $S$. pneumoniae may also be the most common etiologic agent in empyema and pleural effusion specimens [26-28]. In order to better under- stand epidemiologic and microbiologic patterns of empyema and pleural effusion among diverse populations of Asian children $<16$ years of age, we undertook a retrospective review of hospital records in four countries.

\section{Methods \\ Overview}

For this study, we selected four tertiary care medical centers specializing in treatment of children: Chang Gung Children's Hospital (Taipei, Taiwan), Beijing Children's Hospital (Beijing, China); Yonsei University Hospital (Seoul, Korea) and the National Pediatric Hospital affiliated with the Ministry of Health (Hanoi, Vietnam). Each provided a representative sample of patients treated at major tertiary care hospitals, maintained patient hospital discharge and laboratory records in computerized databases, and permitted collaboration with experienced clinical researchers. The study protocol was approved by the International Vaccine Institute Institutional Review Board. Local investigators met with hospital clinicians and microbiologists to assess the extent of their experience with complicated pneumonia and routine microbiology laboratory practices for pleural fluid specimen testing. Hospital clinical and microbiology departments were asked to identify and collect information on clinically-diagnosed empyema. Due to variations in hospital record availability, the data collection periods varied somewhat-1995-2004 in China and Korea, 2000-2005 in Taiwan and 1996-2005 in Vietnam.

\section{Laboratory and medical records data collection}

In each hospital, data collection for patients with empyema was restricted to hospitalized patients $<16$ years of age. Hospital microbiologists accessed laboratory databases and record books to compile a listing of pleural effusion and empyema specimens that were tested by microbiologic culture. Collaborating investigators also reviewed computerized microbiology records for reports of culture-negative and culture-positive empyema or pleural effusion specimens and provided lists of organisms isolated in the specimens. In each study hospital, cultures for anaerobes were not routinely performed. In addition, these hospital laboratories did not routinely culture for fungi, mycobacterium and parasites.

International Classification of Diseases (ICD-10) codes were used to conduct searches of computerized hospital discharge record databases in each collaborating hospital. Each hospital's medical records department staff created discharge record databases to identify patients discharged with an ICD-10 diagnostic code corresponding to pyothorax with fistula (J86.0), pyothorax without fistula (J86.9) or pleural effusion (J90). To identify the total number of hospitalized pneumonia patients, we provided a standardized listing of etiology-specific and non-specific ICD-9 
or ICD-10 diagnostic codes. Following exclusion of confidential identifying information such as national registration number, the medical records discharge databases were transferred to the International Vaccine Institute for review and analysis.

\section{Data analyses}

Where possible for each hospital, demographic and hospitalization characteristics were analyzed to describe epidemiologic patterns by age group, date of hospital discharge, type of specimen collected and organism isolated. However, the data on S. pneumoniae in particular from Taiwan did not include information such as age and admission dates. An analysis of specimen collection and patient discharge dates was performed to assess the seasonal distribution of patients with culture-positive and culture-negative specimens. Statistical comparisons were performed to identify significant differences in the distribution of different variables by calculating a 95\% confidence interval and a critical ratio $(Z)$ test with $P$-value (significance level $P<0.05$ ) for the difference between two independent proportions.

\section{Results}

Hospitalizations for empyema and pleural effusion

From the four study hospitals, this review identified a total of 1,379 patients diagnosed with empyema or pleural effusion (Table 1): 665 in Vietnam, 461 in China, 134 in Korea and 119 in Taiwan. The number of hospitalizations due to empyema and pleural effusion increased over time, at least up to 2002, with some yearly fluctuations. However, there was no significant change over time in number of hospitalizations due to empyema and pleural effusion among the four study hospitals. Overall in the four countries, $60 \%$ of patients with empyema and pleural effusion were male. A preponderance of males was noted in all countries (62\% in China and Korea and 57\% in Taiwan and Vietnam).
Among the 1,379 patients, 305 (22\%) were diagnosed with empyema and 1,074 (78\%) with pleural effusion (Table 2). In China, all patients were recorded as having pleural effusion. In Vietnam and Korea, children with pleural effusion outnumbered those classified with empyema; 4 to 1 in Vietnam and 2 to 1 in Korea. Hospitalization data from Taiwan showed the lowest frequency of children with pleural effusion - only $4 \%$, while $96 \%$ were coded as empyema. To put our results for empyema and pleural effusion in context, we identified the total number of hospitalizations for pneumonia among children $<15$ years of age in each hospital. The Vietnam study hospital had the most pneumonia hospitalizations ( $\mathrm{n}=$ 54,673 ) followed by $14,770,12,254$ and 11,193 in the China, Taiwan and Korea study hospitals, respectively. Among these pneumonia hospitalizations, empyema and pleural effusion were most commonly identified in China (3.1\%) followed by Vietnam and Korea (1.2\% each) and Taiwan $(1.0 \%)$.

Overall, 21\% of all patients diagnosed with empyema or pleural effusion in the four study hospitals were less than 1 year of age (Table 2). The Vietnam study hospital had the highest proportion of patients (29\%) with empyema and pleural effusion in that age group followed by Korea (24\%) and China and Taiwan (12\% each). Children with pleural effusions in Korea and Vietnam were significantly younger than in China $(P<.0001)$. Notably, although the relative proportion of patients classified with empyema or pleural effusion was markedly different in China and Taiwan, nonetheless the proportion of patients (12\%) less than 1 year of age was identical. The mean age of children with empyema and pleural effusion in China was 7.6 years compared with 5.1, 4.1 and 3.2 years in Vietnam, Taiwan and Korea, respectively.

There was no obvious seasonality in the occurrence of pleural effusion and empyema or in pneumococcal

Table I: Distribution of patients with empyema or pleural effusion during hospitalization in four hospitals in China, Korea, Taiwan and Vietnam, 1995-2005.

\begin{tabular}{|c|c|c|c|c|c|}
\hline \multirow[t]{2}{*}{ Time Period } & \multicolumn{4}{|c|}{ Hospital Location } & \multirow[t]{2}{*}{ Total } \\
\hline & Vietnam* & Chinat & Korea ${ }^{\dagger}$ & Taiwan $\ddagger$ & \\
\hline $1995-1996$ & $48(7 \%)$ & $76(16 \%)$ & $19(14 \%)$ & -- & $143(10 \%)$ \\
\hline $1997-1998$ & $113(17)$ & $114(25)$ & $7(5)$ & -- & $234(17)$ \\
\hline 1999-2000 & $146(22)$ & $71(15)$ & $31(23)$ & $18(15)$ & $266(19)$ \\
\hline $200 \mathrm{I}-2002$ & $179(27)$ & $83(18)$ & $35(26)$ & $51(43)$ & $348(25)$ \\
\hline $2003-2005$ & $179(27)$ & $117(25)$ & $42(31)$ & $50(42)$ & $388(28)$ \\
\hline Total & $665(100)$ & $46 I(100)$ & $134(100)$ & $119(100)$ & $1,379(100)$ \\
\hline
\end{tabular}

*Vietnam hospital data were available for 10 years (1996-2005).

tChina and Korea hospital data were available for 10 years (1995-2004).

‡Taiwan hospital data were only available for 6 years (2000-2005). 
Table 2: Age distribution of hospitalized children with empyema and pleural effusion in China, Korea, Taiwan and Vietnam.

\begin{tabular}{|c|c|c|c|c|c|c|c|c|c|}
\hline \multirow[t]{2}{*}{ Age group } & \multicolumn{2}{|c|}{ Vietnam N (\%) } & \multicolumn{2}{|c|}{ China N (\%) } & \multicolumn{2}{|c|}{ Korea N (\%) } & \multicolumn{2}{|c|}{ Taiwan N (\%) } & \multirow[t]{2}{*}{ Total N (\%) } \\
\hline & Empyema & Pleural effusion & Empyema & Pleural effusion & Empyema & Pleural effusion & Empyema & Pleural effusion & \\
\hline I & $50(35.7)$ & $140(26.7)$ & -- & $56(12.1)$ & $6(11.8)$ & $26(3 \mid .3)$ & $13(11.4)$ & I (20.0) & $292(21.2)$ \\
\hline 2 & $31(22.1)$ & $64(12.2)$ & -- & $25(5.4)$ & $16(31.4)$ & $17(20.5)$ & $8(7.0)$ & I (20.0) & 162 (11.7) \\
\hline 3 & $15(10.7)$ & $32(6.1)$ & -- & $21(4.6)$ & $7(13.7)$ & $12(14.5)$ & $19(16.7)$ & $0(0)$ & $106(7.7)$ \\
\hline 4 & $14(10.0)$ & $30(5.7)$ & -- & $23(5.0)$ & I $(2.0)$ & $4(4.8)$ & $20(17.5)$ & I (20.0) & $93(6.7)$ \\
\hline 5 & $5(3.6)$ & $28(5.3)$ & -- & $31(6.7)$ & $2(3.9)$ & $5(6.0)$ & $24(21.1)$ & $0(0)$ & $95(6.9)$ \\
\hline 6 & $2(1.4)$ & $12(2.3)$ & -- & $36(7.8)$ & $5(9.8)$ & $0(0)$ & $11(9.6)$ & $0(0)$ & $66(4.8)$ \\
\hline 7 & $2(1.4)$ & $21(4.0)$ & -- & 41 (8.9) & $0(0)$ & I (I.2) & $9(7.9)$ & $0(0)$ & $74(5.4)$ \\
\hline 8 & $3(2.1)$ & $18(3.4)$ & -- & $48(10.4)$ & $3(5.9)$ & $0(0)$ & $3(2.6)$ & $0(0)$ & $75(5.4)$ \\
\hline 9 & $2(1.4)$ & $25(4.8)$ & -- & $35(7.6)$ & I (2.0) & $5(6.0)$ & $0(0)$ & I (20.0) & $69(5.0)$ \\
\hline 10 & $4(2.9)$ & $36(6.9)$ & -- & $35(7.6)$ & $2(3.9)$ & $2(2.4)$ & $\mathrm{I}(0.9)$ & $0(0)$ & $80(5.8)$ \\
\hline 11 & $2(1.4)$ & $20(3.8)$ & -- & $22(4.8)$ & $0(0)$ & $0(0)$ & I (0.9) & $0(0)$ & 45 (3.3) \\
\hline 12 & $6(4.3)$ & $34(6.5)$ & -- & $24(5.2)$ & $2(3.9)$ & I (I.2) & I (0.9) & $0(0)$ & $68(4.9)$ \\
\hline 13 & I (0.7) & $27(5.1)$ & -- & $36(7.8)$ & I (2.0) & $0(0)$ & $2(1.8)$ & I (20.0) & $68(4.9)$ \\
\hline 14 & I (0.7) & $22(4.2)$ & -- & $23(5.0)$ & $3(5.9)$ & $6(7.2)$ & $0(00)$ & $0(0)$ & $55(4.0)$ \\
\hline 15 & $2(1.4)$ & $16(3.0)$ & -- & $5(1.1)$ & $2(3.9)$ & $4(4.8)$ & $2(1.8)$ & $0(0)$ & $31(2.2)$ \\
\hline Total & $140(100)$ & $525(100)$ & -- & $46 I(100)$ & $51(100)$ & $83(100)$ & $114(100)$ & $5(100)$ & $1,379(100)$ \\
\hline
\end{tabular}

NOTE. Data for China and Korea are for 1995-2004; for Taiwan, 2000-2005; and Vietnam, 1996-2005.

NOTE: Specimen type in China was not stratified by appearance.

empyema in these four countries. Overall, children with empyema and pleural effusion were more likely to be hospitalized in China during the months of May, June and December (Figure 1), while in Korea, more hospitalizations occurred during May, July and October. In Vietnam, June and September were the most common months for hospitalizations for empyema and pleural effusion.

\section{Culture-positive and culture-negative pleural fluid and empyema specimens}

A total of 1,379 empyema $(\mathrm{n}=310)$ and pleural effusion ( $\mathrm{n}=1,069)$ specimens were tested by bacterial culture, and $71 \%(n=980)$ were negative for any bacterial organism (Table 3). Ninety-two percent of Chinese specimens tested negative compared with $75 \%$ that were culture-negative in Vietnam, $28 \%$ in Taiwan and $19 \%$ in Korea. Among the 310 empyema specimens, $61 \%(n=188)$ were culture-positive compared with $20 \%(\mathrm{n}=211)$ of pleural effusion specimens that were culture-positive $(P<0.05)$. If the 211 children with culture-positive pleural effusion specimens are grouped into the empyema category, the percentage of culture-positive specimens increased from $61 \%$ to $72 \%(P<0.05)$.

$S$. aureus was the most common organism isolated in Korea and Vietnam $(29 \%$ and $48 \%$, of all positive bacterial isolates, respectively), while $S$. pneumoniae predominated in Taiwan (77\% of all positive bacterial isolates) (Table 4). No single pathogen dominated among the few culture-positive samples from China. Acinetobacter and Pseudomonas organisms was the $2^{\text {nd }}$ and $3^{\text {rd }}$ most common pathogens reported in Korea ( $28 \%$ and $11 \%$ of all positive bacterial isolates, respectively), followed by $S$. pneumoniae ( $8 \%$ of all positive bacterial isolates). In Vietnam, Klebsiella and Pseudomonas species were isolated in $17 \%$ and $11 \%$ of all positive bacterial isolates. S. pneumoniae was isolated from 83 patients including $66(80 \%)$ in Taiwan, $9(11 \%)$ in Korea, $5(6 \%)$ in China and $3(3 \%)$ in Vietnam. Of the 83 pneumococcal isolates, $82 \%(n=68)$ were from empyema cases, mostly from Taiwan, compared to $18 \%(n=15)$ from pleural effusion cases.

\section{Discussion}

Our study results show that pleural effusion and empyema occur in Asia among young children at rates similar to those observed elsewhere (1-3\% of pneumonia admissions) [29-31]. However, the clinical differentiation between pleural effusion and empyema may be interpreted differently from one country to another, as suggested by the great difference in the proportion of the two types reported in the four countries studied. For example, in China, $100 \%$ of the pleural effusion and empyema cases were coded only as pleural effusion, but it is likely that these included many empyema cases. In contrast, in Taiwan, only $4 \%$ of the cases were coded as pleural effusion, suggesting either that virtually no pleural fluid samples were taken from children diagnosed with uncomplicated pleural effusions or that all patients from whom samples are taken are automatically coded as "empyema". In Korea and Vietnam, the proportions were more mixed, but coding for pleural effusion nonetheless predominated. Regardless of the distinction, these find- 

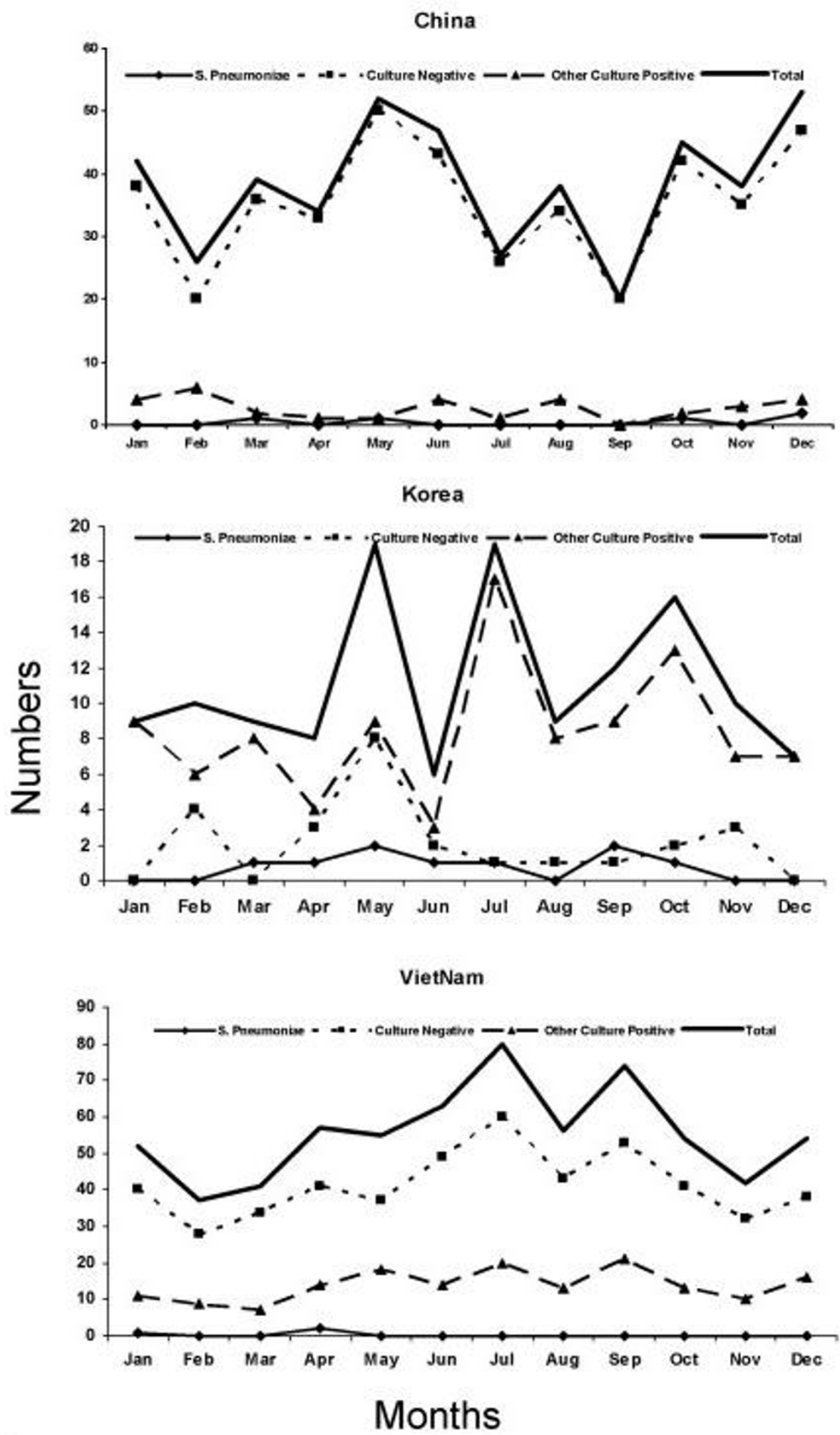

Figure I

Monthly distribution of microbiologic culture results from testing of empyema and pleural fluid specimens in China, Korea and Vietnam.**China and Korea (I 995 to 2004); Taiwan (2000 to 2005) and Vietnam (I 996 to 2005 ). 
Table 3: Organisms identified in empyema and pleural effusion specimens from China, Korea, Taiwan and Vietnam, $1995-2005$.

\begin{tabular}{lccc}
\hline Cultured Organism & Empyema N (\%) & Pleural effusion N (\%) & Total N (\%) \\
\hline Culture negative & $122(39)$ & $858(80)$ & $980(71)$ \\
Gram negative & $51(17)$ & $104(10)$ & $155(11)$ \\
Gram positive & $68(22)$ & $15(1)$ & $83(6)$ \\
$\quad$ S. pneumoniae & $69(22)$ & $92(9)$ & $161(12)$ \\
$\quad$ Others & $310(100)$ & $1,069(100)$ & $1,379(100)$ \\
\hline Total & & & \\
\hline
\end{tabular}

ings emphasize the importance of looking at coding for both pleural effusion and empyema in order to understand the epidemiology of complicated pneumonias.

In this review, one-third of the empyema patients identified were less than 2 years of age confirming that empyema may be more likely to occur in young children than in older children. In India, one-third of hospitalized children with empyema were $<5$ years of age [26]. The mean age ( $4 \sim 5$ years) of children with empyema and pleural effusion in our study was similar to findings elsewhere [32-34].

The absence of a distinct seasonality in the distribution of empyema patients in this study suggests weather may not be an important contributing factor or that the etiologic agents of empyema and pleural effusions specimens could be a heterogeneous group of infectious agents. This conclusion is supported, in part, by data from microbiologic cultures of empyema and pleural fluid showing a wide

Table 4: Distribution of isolates in empyema and pleural effusion specimens by country.

\begin{tabular}{|c|c|c|c|c|c|}
\hline Empyema or Pleural Fluid Isolates & $\begin{array}{l}\text { Vietnam } \\
(\mathrm{n}=665)\end{array}$ & $\begin{array}{c}\text { China } \\
(n=46 \mathrm{I})\end{array}$ & $\begin{array}{c}\text { Korea } \\
(n=134)\end{array}$ & $\begin{array}{l}\text { Taiwan } \\
(\mathrm{n}=119)\end{array}$ & $\begin{array}{c}\text { Total } \\
(\mathrm{n}=1,379)\end{array}$ \\
\hline Culture negative & $496(74.6)$ & $424(92.0)$ & $25(18.7)$ & $33(27.7)$ & $978(70.9)$ \\
\hline Staphylococcus aureus & $81(12.2)$ & $7(1.5)$ & $32(23.9)$ & $6(5.0)$ & $126(9.1)$ \\
\hline Streptococcus pneumoniae & $3(0.5)$ & $5(1.1)$ & $9(6.7)$ & $66(55.5)$ & $83(6.0)$ \\
\hline Pseudomonas aeruginosa & $19(2.9)$ & $5(1.1)$ & $12(9.0)$ & I (0.8) & $37(2.7)$ \\
\hline Klebsiella spp. & $28(4.2)$ & $4(0.9)$ & $3(2.2)$ & $0(0)$ & $35(2.5)$ \\
\hline Acinetobacter spp. & $4(0.6)$ & $0(0)$ & $30(22.4)$ & $0(0)$ & $34(2.5)$ \\
\hline Escherichia coli & $9(1.4)$ & $\mathrm{I}(0.2)$ & $2(1.5)$ & $\mathrm{I}(0.8)$ & $13(0.9)$ \\
\hline Enterococcus spp. & $2(0.3)$ & $\mathrm{I}(0.2)$ & $8(6.0)$ & $0(0)$ & $\mathrm{II}(0.8)$ \\
\hline Haemophilus influenzae type b & $9(1.4)$ & $0(0)$ & $\mathrm{I}(0.7)$ & $4(3.4)$ & $14(1.0)$ \\
\hline Enterobacter spp. & $\mathrm{I}(0.2)$ & $2(0.4)$ & $6(4.5)$ & $0(0)$ & $9(0.7)$ \\
\hline Streptococcus spp. & $8(1.2)$ & $0(0)$ & $\mathrm{I}(0.7)$ & $\mathrm{I}(0.8)$ & $10(0.7)$ \\
\hline Stenotrophomonas maltophilia & $0(0)^{\prime}$ & $\mathrm{I}(0.2)$ & $3(2.2)$ & $0(0)$ & $4(0.3)$ \\
\hline Mycoplasma pneumoniae & $0(0)$ & $0(0)$ & $0(0)$ & $4(3.4)$ & $4(0.3)$ \\
\hline Corynebacterium spp. & $0(0)$ & $2(0.4)$ & $0(0)$ & $0(0)$ & $2(0.2)$ \\
\hline Candida albicans & $2(0.3)$ & $0(0)$ & $\mathrm{I}(0.7)$ & $0(0)$ & $3(0.2)$ \\
\hline Citrobacter spp. & $2(0.3)$ & $0(0)$ & $0(0)$ & $0(0)$ & $2(0.2)$ \\
\hline Fungi & $0(0)$ & $2(0.5)$ & $0(0)$ & $0(0)$ & $2(0.2)$ \\
\hline Micrococcus spp. & $0(0)$ & $2(0.4)$ & $0(0)$ & $0(0)$ & $2(0.2)$ \\
\hline Burkholderia cepacia & $0(0)$ & $0(0)$ & $\mathrm{I}(0.7)$ & $0(0)$ & $I(0.1)$ \\
\hline Haemophilus parainfluenzae & $0(0)$ & $\mathrm{I}(0.2)$ & $0(0)$ & $0(0)$ & $\mathrm{I}(0.1)$ \\
\hline Anaerobic & $I(0.2)$ & $0(0)$ & $0(0)$ & $0(0)$ & $\mathrm{I}(0.1)$ \\
\hline Neisseria spp. & $0(0)$ & $\mathrm{I}(0.2)$ & $0(0)$ & $0(0)$ & $\mathrm{I}(0.1)$ \\
\hline Staphylococcus epidermidis & $0(0)$ & $\mathrm{I}(.02)$ & $0(0)$ & $0(0)$ & $\mathrm{I}(0.1)$ \\
\hline Staphylococcus intermedius & $0(0)$ & $I(0.2)$ & $0(0)$ & $0(0)$ & $\mathrm{I}(0.1)$ \\
\hline viridans group streptococci & $0(0)$ & $\mathrm{I}(0.2)$ & $0(0)$ & $0(0)$ & $\mathrm{I}(0.1)$ \\
\hline Veillonella spp. & $0(0)$ & $0(0)$ & $0(0)$ & $\mathrm{I}(0.8)$ & $I(0.1)$ \\
\hline Clostridium spp. & $0(0)$ & $0(0)$ & $0(0)$ & $\mathrm{I}(0.8)$ & $\mathrm{I}(0.1)$ \\
\hline Prevotella spp. & $0(0)$ & $0(0)$ & $0(0)$ & $\mathrm{I}(0.8)$ & $\mathrm{I}(0.1)$ \\
\hline Total & $665(100)$ & $461(100)$ & $134(100)$ & $119(100)$ & $1,379(100)$ \\
\hline
\end{tabular}


variety of Gram-positive and Gram-negative organisms as well as fungi and culture-negative specimens.

Our study identified several children whose empyema or pleural fluid cultures grew bacterial pathogens normally associated with community-acquired lower respiratory tract disease including Hib, S. pneumoniae and $S$. aureus [35-37]. These findings are consistent with a growing number of reports suggesting that much childhood empyema could be vaccine-preventable $[38,39]$. In our study hospitals, data on bacterial species also suggest either that a large proportion of children may acquire Gram-negative pathogens as nosocomial infections or that a number of bacterial isolates are contaminants of laboratory cultures $[40,41]$. Previous reviews or case series describing bacterial organisms isolated from children with empyema suggest that Gram-positive as well as Gram-negative organisms may invade the pleural space $[42,43]$.

In our study, a high proportion (71\%) of all empyema and pleural fluid specimens grew no bacterial pathogen. This finding is consistent with a number of previous studies suggesting that the negative cultures are not the result of limitations in routine microbiology laboratory procedures. The negative cultures more likely are due to the widespread use of antibiotics (including inappropriately chosen or dosed antibiotics) as well the potential for severe viral lower respiratory tract disease to be associated with pleural effusion or bacterial superinfections resulting in necrotizing pneumonia and empyema $[44,45]$. This study collected data from existing computerized hospital discharge databases and laboratory records but individual patient medical records were not accessed to obtain information on prior treatment with antibiotics. In general, in our previous studies, we have found that parent- or patient-reported prior use of antibiotics is often not recorded in medical records. In addition, the high rate of negative cultures may be due to the presence of fastidious organisms such as anaerobic bacteria [46]. Based on our previous studies in Asia, we have found that many hospital laboratories do not use anaerobic culture media. According to a recent study reported by Song JH et al, the prevalence of penicillin resistance in $S$. pneumoniae isolates was $71.4 \%$ in Vietnam followed by Korea (54.8\%), Taiwan $(38.6 \%)$ and China (23.4\%) [47]. Given the high proportion of bacterial culture-negative pleural fluid specimens, a more complete assessment of parapneumonic pleural effusions or empyema in prospective studies could apply non-culture-based antigen detection or polymerase chain reaction tests to detect both bacterial and viral pathogens. These tests have been used to identify children with culture-negative pneumococcal infections [43,48-50]. These sensitive diagnostic tools can help us to better understand the burden of disease, trends over time, epide- miological differences among countries, patient demography, symptomatology, etiological agents and rational treatment. Unfortunately, at present, these laboratory techniques are only generally available in research laboratories.

A number of investigators have shown that laboratory testing of pleural fluid or empyema specimens in children with pneumonia can provide important insights into the origins of the pneumonia [51,52]. In Asia relatively few children hospitalized with serious pneumonia undergo thoracocentesis diagnostic procedures to identify pathogens in pleural or empyema fluid, which are relatively less culturally acceptable in Asian populations [53]. Nevertheless, given the number of children identified in our retrospective survey, prospective multi-center studies in Asia are likely to yield substantial numbers of patients with empyema or complicated pleural effusions and shed light on the etiological agent associated with parapneumonic empyema and pleural effusions.

In this study, we found that children with empyema were significantly more likely to have positive bacterial cultures compared with children in whom pleural effusion specimens were collected. These data are consistent with previous studies suggesting that empyema fluid is the result of established infections and inflammatory reactions $[28,54]$. However, given the fact that clinicians in Asia have also found it necessary to collect clinical specimens from patients with pleural effusions, it is likely that prospective studies that include an evaluation of bacterial pathogens in pleural effusions specimens will yield a more accurate picture of the total burden of disease associated with invasive bacterial pneumonia and parapneumonic bacterial infections.

This study has some limitations. First, as a retrospective review, our data collection, analysis and reporting were restricted to that available in hospital databases or logbooks. Thus, for some years of data, incomplete patient information precluded further analysis. Computerized hospital administrative databases were accessed by collaborating study investigators. Nevertheless, in some hospitals we found that current levels of data entry limited the amount of clinical and historical data available. The increasing use of electronic medical records in Asia suggests that additional patient clinical and laboratory data are likely to be available in a number of countries in coming years. Finally, because the hospitals in our review did not record more than one ICD-10 diagnostic code, we were unable to determine other clinical conditions that the children may have had at the time of their hospitalization and thus we could not determine the proportion of children with pneumonia or lower respiratory tract infec- 
tions among those who had empyema or pleural fluid specimens collected.

Similarly, as the hospital laboratories did only limited testing, there was no means to identify underlying causes of lower respiratory tract disease in infants and young children. In addition, most clinical laboratories in the study countries do not routinely preserve bacterial isolates from pleural fluid specimens because they lack resources and awareness of the utility of such specimens for research and advancement of treatment.

\section{Conclusion}

Future incidence studies in such hospitals to determine the true burden of parapneumonic empyema may be feasible if catchment areas for study sites can be well-defined. Recent studies from France $[42,55]$ suggest that the incidence of empyema may vary over time. Our results suggest that prospective surveillance for pneumonia with empyema or pleural effusions could be established as part of larger surveillance for severe bacterial infections including meningitis and sepsis. Surveillance for invasive bacterial diseases can be improved by: a) applying standardized case definitions; b) create, disseminate and implement standard pediatric guidelines for treatment of pneumonia, empyema and other syndromes associated with invasive bacterial diseases; c) requiring report of clinical laboratory specimens from normally sterile sites that are culture-positive for Hib, S. pneumoniae, $N$. meningitidis and other invasive bacterial pathogens; and d) implementing standard operating procedures that maximize capacity for detection of invasive bacterial pathogens in hospital laboratories. Future prospective studies of empyema will benefit from standardized case definitions and coding practices for empyema as well as pleural effusion.

\section{Competing interests}

The authors declare that they have no competing interests.

\section{Authors' contributions}

$\mathrm{BN}$ and PEK conceived and designed the study, assisted with data collection, performed the data analyses and drafted the study manuscript. DEY, DDA, C-HC and XS implemented standardized methods for hospital data collection, verified data sources and accuracy and participated in writing of the study manuscript. LJ, TLN, HLB and WPH provided input into data collection, reviewed outputs from data analysis and assisted in editing of the study manuscript.

\section{Acknowledgements}

This study was supported by the Governments of Kuwait, the Republic of Korea and Sweden as well as through a research grant from GlaxoSmithKline Biologicals, Rixensart, Belgium. We thank Kathy Murray for her editorial comments and Min Kyoung Oh for her preparation of this manuscript submission.
Results reported in this manuscript were presented in part at the $5^{\text {th }}$ International Pneumococci and Pneumococcal Disease Symposium (ISPPD5), Alice Springs, Australia, April 3 to 6, 2006.

\section{References}

I. Rudan I, Tomaskovic L, Boschi-Pinto C, Campbell H: Global estimate of the incidence of clinical pneumonia among children under five years of age. Bull World Health Organ 2004, 82(1 2):895-903.

2. Williams BG, Gouws E, Boschi-Pinto C, Bryce J, Dye C: Estimates of world-wide distribution of child deaths from acute respiratory infections. Lancet Infect Dis 2002, 2(I):25-32.

3. UNICEF: Pneumonia: The Forgotten Killer of Children. UNICEF/WHO; 2006: I-40.

4. Bechamps GJ, Lynn HB, Wenzl JE: Empyema in children: review of mayo clinic experience. Mayo Clin Proc 1970, 45(I):43-50.

5. Todd JK, Bruhn FW: Severe Haemophilus influenzae infections. Am J Dis Child I975, I 29(5):607-6I I.

6. Byington $\mathrm{CL}$, Samore MH, Stoddard GJ, Barlow S, Daly J, Korgenski K, Firth S, Glover D, Jensen J, Mason EO, Shutt CK, Pavia AT: Temporal trends of invasive disease due to Streptococcus pneumoniae among children in the intermountain west: emergence of nonvaccine serogroups. Clin Infect Dis 2005, 4I (I):2I-29.

7. Eastham KM, Freeman R, Kearns AM, Eltringham G, Clark J, Leeming J, Spencer DA: Clinical features, aetiology and outcome of empyema in children in the north east of England. Thorax 2004, 59(6):522-525

8. Finley C, Clifton J, Fitzgerald JM, Yee J: Empyema: an increasing concern in Canada. Can Respir J 2008, I 5(2):85-89.

9. Munoz-Almagro C, Jordan I, Gene A, Latorre C, Garcia-Garcia JJ, Pallares R: Emergence of invasive pneumococcal disease caused by nonvaccine serotypes in the era of 7 -valent conjugate vaccine. Clin Infect Dis 2008, 46(2): I74- 182.

10. Spencer DA, Iqbal SM, Hasan A, Hamilton L: Empyema thoracis is still increasing in UK children. Bmj 2006, 332(7553): I 333.

II. Engum SA: Minimal access thoracic surgery in the pediatric population. Semin Pediatr Surg 2007, I 6(I): |4-26.

12. Ulku R, Onen A, Onat S, Kilinc N, Ozcelik C: Intrapleural fibrinolytic treatment of multiloculated pediatric empyemas. Pediatr Surg Int 2004, 20(7):520-524.

13. Sonnappa S, Cohen G, Owens CM, van Doorn C, Cairns J, Stanojevic $S$, Elliott MJ, Jaffe A: Comparison of urokinase and videoassisted thoracoscopic surgery for treatment of childhood empyema. Am J Respir Crit Care Med 2006, I 74(2):22I-227.

14. Wexler ID, Knoll S, Picard E, Villa Y, Shoseyov D, Engelhard D, Kerem $\mathrm{E}$ : Clinical characteristics and outcome of complicated pneumococcal pneumonia in a pediatric population. Pediatr Pulmonol 2006, 4 I (8):726-734.

15. Aebi C, Ahmed A, Ramilo O: Bacterial complications of primary varicella in children. Clin Infect Dis 1996, 23(4):698-705.

16. Nelson JD: Pleural empyema. Pediatr Infect Dis I985, 4(3 Suppl):S3 I-3.

17. Hadfield TL, Monson MH, Wachsmuth IK: An outbreak of antibiotic-resistant Salmonella enteritidis in Liberia, West Africa. J Infect Dis 1985, I 5 I(5):790-795.

18. Tumwine JK: Lung abscess in children in Harare, Zimbabwe. East Afr Med J 1992, 69( 1 0):547-549.

19. Kim NH, Lee J, Lee SJ, Lee H, Kim KH, Park SE, Lee HJ: Immunogenicity and safety of pneumococcal 7-valent conjugate vaccine (diphtheria CRM( 197) protein conjugate; Prevenar ) in Korean infants: differences that are found in Asian children. Vaccine 2007, 25(45):7858-7865.

20. Ho CF, Lin TY: Pneumococcal vaccines. Chang Gung Med J 2005, 28(I I):765-772.

21. Arancibia MF, Vega-Briceno LE, Pizarro ME, Pulgar D, Holmgren N, Bertrand P, Rodriguez JL, Sanchez I: [Empyema and pleural effusion in children]. Rev Chilena Infectol 2007, 24(6):454-46I.

22. Byington CL, Spencer LY, Johnson TA, Pavia AT, Allen D, Mason EO, Kaplan S, Carroll KC, Daly JA, Christenson JC, Samore MH: An epidemiological investigation of a sustained high rate of pediatric parapneumonic empyema: risk factors and microbiological associations. Clin Infect Dis 2002, 34(4):434-440.

23. Roxburgh CS, Youngson GG, Townend JA, Turner SW: Trends in pneumonia and empyema in Scottish children in the past 25 years. Arch Dis Child 2008, 93(4):316-318. 
24. Chonmaitree T, Powell KR: Parapneumonic pleural effusion and empyema in children. Review of a 19-year experience, 19621 980. Clin Pediatr (Phila) 1983, 22(6):4|4-419.

25. McLaughlin FJ, Goldmann DA, Rosenbaum DM, Harris GB, Schuster SR, Strieder DJ: Empyema in children: clinical course and longterm follow-up. Pediatrics 1984, 73(5):587-593.

26. Baranwal AK, Singh M, Marwaha RK, Kumar L: Empyema thoracis: a I0-year comparative review of hospitalised children from south Asia. Arch Dis Child 2003, 88(I I):I009-I0I4.

27. Sarihan H, Cay A, Aynaci M, Akyazici R, Baki A: Empyema in children. J Cardiovasc Surg (Torino) 1998, 39(I): I I3-I I6.

28. Shen YH, Hwang KP, Niu CK: Complicated parapneumonic effusion and empyema in children. J Microbiol Immunol Infect 2006, 39(6):483-488.

29. Avansino JR, Goldman B, Sawin RS, Flum DR: Primary operative versus nonoperative therapy for pediatric empyema: a meta-analysis. Pediatrics 2005, I I 5(6): | 652-I659.

30. Hardie W, Bokulic R, Garcia VF, Reising SF, Christie CD: Pneumococcal pleural empyemas in children. Clin Infect Dis 1996, 22(6): 1057-1063.

31. Sonnappa S, Jaffe A: Treatment approaches for empyema in children. Paediatr Respir Rev 2007, 8(2): I64-I70.

32. Cirino LM, Gomes FM, Batista BN: The etiology of extensive pleural effusions with troublesome clinical course among children. Sao Paulo Med J 2004, I 22(6):269-272.

33. Schultz KD, Fan LL, Pinsky J, Ochoa L, Smith EO, Kaplan SL, Brand ML: The changing face of pleural empyemas in children: epidemiology and management. Pediatrics 2004, I | 3(6): | 735- I 740.

34. Soysal O, Topcu S, Tastepe I, Kaya S, Cetin G: Childhood chronic pleural empyema: a continuing surgical challenge in developing countries. Thorac Cardiovasc Surg 1998, 46(6):357-360.

35. Greenwood B: Epidemiology of acute lower respiratory tract infections, especially those due to Haemophilus influenzae type b, in The Gambia, west Africa. J Infect Dis 1992, I 65 Suppl I:S26-8.

36. Jaffe A, Balfour-Lynn IM: Management of empyema in children. Pediatr Pulmonol 2005, 40(2): |48-I56.

37. Yin CC, Huah LW, Lin JT, Goh A, Ling H, Moh CO: Lower respiratory tract infection in hospitalized children. Respirology 2003, 8(I):83-89.

38. Byington CL, Korgenski K, Daly J, Ampofo K, Pavia A, Mason EO: Impact of the pneumococcal conjugate vaccine on pneumococcal parapneumonic empyema. Pediatr Infect Dis J 2006, 25(3):250-254.

39. Fletcher $M$, Leeming J, Cartwright K, Finn A: Childhood empyema: limited potential impact of 7 -valent pneumococcal conjugate vaccine. Pediatr Infect Dis J 2006, 25(6):559-560.

40. Cremonesini $\mathrm{D}$, Thomson $\mathrm{AH}$ : How should we manage empyema: antibiotics alone, fibrinolytics, or primary videoassisted thoracoscopic surgery (VATS)? Semin Respir Crit Care Med 2007, 28(3):322-332.

41. Nan DN, Fernandez-Ayala M, Farinas-Alvarez C, Mons R, Ortega FJ, Gonzalez-Macias J, Farinas MC: Nosocomial infection after lung surgery: incidence and risk factors. Chest 2005, I 28(4):2647-2652.

42. Bekri H, Cohen R, Varon E, Madhi F, Gire R, Guillot F, Delacourt C: [Streptococcus pneumoniae serotypes involved in children with pleural empyemas in France]. Arch Pediatr 2007 I 4(3):239-243.

43. Le Monnier A, Carbonnelle E, Zahar JR, Le Bourgeois M, Abachin E, Quesne G, Varon E, Descamps P, De Blic J, Scheinmann P, Berche P, Ferroni A: Microbiological diagnosis of empyema in children: comparative evaluations by culture, polymerase chain reaction, and pneumococcal antigen detection in pleural fluids. Clin Infect Dis 2006, 42(8): I | 35- I | 40.

44. Guyon G, Allal H, Lalande M, Rodiere M: [Pleural empyema in children: Montpellier's experience]. Arch Pediatr 2005, I 2 Suppl I:S54-7.

45. Porcel JM, Ruiz-Gonzalez A, Falguera M, Nogues A, Galindo C, Carratala J, Esquerda $A$ : Contribution of a pleural antigen assay (Binax NOW) to the diagnosis of pneumococcal pneumonia. Chest 2007, I 3 I(5): |442-|447.

46. Brook I: Microbiology of empyema in children and adolescents. Pediatrics 1990, 85(5):722-726.

47. Song JH, Jung SI, Ki HK, Shin MH, Ko KS, Son JS, Chang HH, Kim SW, Lee H, Kim YS, Oh WS, Peck KR, Chongthaleong A, Lalitha MK, Per- era J, Yee TT, Jamal F, Kamarulzaman A, Carlos CC, So T: Clinical outcomes of pneumococcal pneumonia caused by antibioticresistant strains in asian countries: a study by the Asian Network for Surveillance of Resistant Pathogens. Clin Infect Dis 2004, 38(I I): I570-1578.

48. Lahti E, Mertsola J, Kontiokari T, Eerola E, Ruuskanen O, Jalava J: Pneumolysin polymerase chain reaction for diagnosis of pneumococcal pneumonia and empyema in children. Eur J Clin Microbiol Infect Dis 2006, 25(I 2):783-789.

49. Rahman I, Adcock IM: Oxidative stress and redox regulation of lung inflammation in COPD. Eur Respir J 2006, 28(I):219-242

50. Sahn SA: Diagnosis and management of parapneumonic effusions and empyema. Clin Infect Dis 2007, 45(I I): | 480- | 486.

51. Peltola V, Alanen M, Mertsola J, Ruuskanen O: [Empyema-increasingly common complication connected to pneumonia in children]. Duodecim 2004, I 20( I 4): I77|-|777.

52. Vuori-Holopainen E, Salo E, Saxen H, Hedman K, Hyypia T, Lahdenpera R, Leinonen M, Tarkka E, Vaara M, Peltola H: Etiological diagnosis of childhood pneumonia by use of transthoracic needle aspiration and modern microbiological methods. Clin Infect Dis 2002, 34(5):583-590.

53. Gates RL, Hogan M, Weinstein S, Arca MJ: Drainage, fibrinolytics, or surgery: a comparison of treatment options in pediatric empyema. J Pediatr Surg 2004, 39(I I): I 638- I642.

54. Schiza S, Siafakas NM: Clinical presentation and management of empyema, lung abscess and pleural effusion. Curr Opin Pulm Med 2006, I 2(3):205-2II.

55. Ploton C, Freydiere AM, Benito Y, Bendridi N, Mazzocchi C, Bellon G, Vandenesch F: Streptococcus pneumoniae thoracic empyema in children: rapid diagnosis by using the Binax NOW immunochromatographic membrane test in pleural fluids. Pathol Biol (Paris) 2006, 54(8-9):498-50I.

\section{Pre-publication history}

The pre-publication history for this paper can be accessed here:

http://www.biomedcentral.com/1471-2334/8/90/prepub

Publish with BioMed Central and every scientist can read your work free of charge

"BioMed Central will be the most significant development for disseminating the results of biomedical research in our lifetime. "

Sir Paul Nurse, Cancer Research UK

Your research papers will be:

- available free of charge to the entire biomedical community

- peer reviewed and published immediately upon acceptance

- cited in PubMed and archived on PubMed Central

- yours - you keep the copyright

Submit your manuscript here:

http://www.biomedcentral.com/info/publishing_adv.asp
BioMedcentral 